Discussion Paper No. 904

\title{
TRUST AND HAPPINESS: \\ COMPARATIVE STUDY \\ BEFORE AND AFTER \\ THE GREAT EAST JAPAN EARTHQUAKE
}

\author{
Eiji Yamamura \\ Yoshiro Tsutsui \\ Chisako Yamane \\ Shoko Yamane \\ Nattavudh Powdthavee
}

July 2014

The Institute of Social and Economic Research

Osaka University

6-1 Mihogaoka, Ibaraki, Osaka 567-0047, Japan 


\title{
Trust and Happiness: Comparative Study Before and After the Great East Japan Earthquake
}

\author{
Eiji Yamamura $\cdot$ Yoshiro Tsutsui $\cdot$ Chisako Yamane $\cdot$ Shoko Yamane $\cdot$ Nattavudh \\ Powdthavee
}

\begin{abstract}
The positive relationship between trust and happiness has been demonstrated by the literature. However, it is not clear how much this relationship depends on environmental conditions. The Great East Japan Earthquake of 2011 is considered one of the most catastrophic events in human history. This disaster caused not only physical damage for Japanese people, but also perceived damage. Using individual-level panel data from Japan covering the period 2009-2012, this paper attempts to probe how the relationship between trust and happiness was influenced by the Great East Japan Earthquake by comparing the same individuals before and after the earthquake. A fixed-effects estimation showed that there is a statistically well-determined positive relationship between trust and happiness and this relationship was strengthened by disaster, especially for residents in the damaged area. We argue that social trust is a substitute for formal institutions and markets, which mitigates the effect of disaster-related shock on psychological conditions such as happiness. Therefore, a trustful society is invulnerable to a gigantic disaster.
\end{abstract}

Keywords: Trust $\cdot$ Happiness $\cdot$ Disaster $\cdot$ Great East Japan Earthquake

\section{E. Yamamura}

1Seinan Gakuin University. 6-2-92, Nishijin Sawara-ku, Fukuoka 814-8511, Japan

e-mail: yamaei@seinan-gu.ac.jp

Y. Tsutsui

Konan University. 8-9-1 Okamoto Higashinada-ku, Kobe 658-8501, Japan

e-mail: tsutsui@center.konan-u.ac.jp

C. Yamane

Okayama Shoka University. 2-10-1 Tsushima Kyomachi Kitaku, Okayama 700-8601, Japan

e-mail: Yamane@po.osu.ac.jp

S. Yamane

Kindai University. 3-4-1 Kowakae Higashi-osaka, Osaka 577-8502, Japan

e-mail: syamane@kindai.ac.jp

N. Powdthavee

CEP, London School of Economics, London, UK; MIAESR, University of Melbourne, Melbourne, Australia

e-mail: N.Powdthavee@1se.ac.uk 
It has become increasingly difficult for researchers to ignore the wealth of benefits that social capital, which can be defined broadly as a combination of social trust, interpersonal networks, and community participation, has on personal well-being (Putnam 1993, 2000). While its benefits for an individual's health status have been well described by the framework of social supports in the health literature (e.g., Kawachi et al. 1997, 1999, 2007), in theory the relationship between social capital and an individual's overall evaluation of quality of life (or subjective well-being [SWB] in general) is not as well developed.

For instance, the relationship between trust and SWB is likely to be context specific. Even if people do not trust others, markets will function well when the law and order, which is based on formal rules, and public authority is reliable, and people enjoy the benefits. However, in a low-trust society, once the law and order is disturbed, people are less likely to make transactions to avoid being cheated. Furthermore, people resort to dishonest behavior or illegal activity such as looting or robbery because of a poorly functioning market, which increases negative externality. Accordingly, trust plays a more important role in reducing negative externality when formal laws are not functioning well.

In 2010, after the Great Haiti Earthquake, "a crowd beat a suspected thief to death and dragged his body through the streets" (Aldrich 2012:24). This shows that a society lacking trust tends to be ruled by violence and terror, which results in a man-made secondary tragedy. Without doubt, the detrimental shock of experiencing a disaster is strengthened by distrustful human relations. In 2005, after Hurricane Katrina in the United States, cooperative behavior was not observed and uprisings and stealing were rampant and prevalent (Kawachi 2013:15-16). In contrast with the Great Haiti Earthquake and Hurricane Katrina, disturbances did not arise immediately after the Great East Japan Earthquake and people endured their difficulties with great patience (Ono 2012; Kawachi 2013). Several economic researchers have investigated the impact of disasters on modern society (e.g., Skidmore and Toya 2002; Anbarci et al. 2005; Eisensee and Strömberg 2007; Kellenberg and Mobarak 2008; Becchetti and Castriota 2010; Sawada and Shimizutani 2007, 2008, 2011). Some have noted that social capital 
played a crucial role in mitigating damage or recovering from the disaster (Yamamura 2010; Aldrich 2012).

Many studies have found a positive relationship between social capital and different measures of SWB (e.g., Putnam 2000; Bjørnskov 2003, 2006; Helliwell 2003, 2006a, 2006b; Powdthavee 2008; Kuroki 2011). ${ }^{1}$ However, the majority of these studies were based on data sets obtained from countries during a relatively stable time period. If SWB is used as the dependent variable and trust is used as the independent variable, a third factor such as individual personality is possibly related to them. This factor causes a spurious correlation between SWB and trust, which results in estimation bias. Suicide rates can be regarded as a proxy for SWB, which is useful for providing an objective measure of social trust. Ten percent of the population in each country thought that others could be trusted, which is associated with a 4.0 per 100,000 drop in the annual suicide rate for males, and a smaller 0.5 per 100,000 drop for females (Helliwell 2006a:473-474). If the relationship between individual-level trust and SWB is examined, the causality is ambiguous. To tackle this problem, Kuroki (2011) examined the effect of regional-level trust on SWB. He found that "if a person is exogenously moved from an 'average-trust' prefecture to the prefecture with the highest trust level (8.6-percentage-point increase in trust), his happiness will increase by 0.16 in a 5-point scale" (Kuroki 2011:455). However, these papers do not deal with the relationship between trust and SWB in an emergent situation.

However, disasters were found to have a sizable impact on subjective perception such as life satisfaction (e.g., Carroll et al. 2009; Luechinger and Saschkly 2009; Becchetti and Castriota 2010). ${ }^{2}$ Researchers have attempted to investigate the psychological impact of the Great East Japan Earthquake on Japanese people (Ishino et al. 2011; Hanaoka et al. 2014; Uchida et al. 2014) and also in German people (Goebel et al. 2013). However, these works do not consider how trust was related to SWB by comparing trust before and after the disaster. Our novel contribution is to make it

\footnotetext{
${ }^{1}$ Ram (2009) did not find a significant association between trust and happiness.

2 An unexpected catastrophe such as a terrorist attack was also found to result in higher levels of mental distress (Metcalfe et al. 2011). The suicide rate is considered as an objective variable for capturing the degree of life satisfaction in society. Matsubayashi et al. (2013) examined the relationship between disaster and suicide rates.
} 
evident that trust plays a greater role in increasing SWB when people suffer the damage caused by an unexpected, devastating shock compared with SWB during a relatively stable time. ${ }^{3}$

The structure of the remaining part of this paper is as follows: section 2 is an overview of the Fukushima accident. Section 3 explains data used in this paper and proposes testable hypotheses, and method. Section 4 reports the estimation results. The final section presents the conclusion.

\section{Overview of the Great East Japan Earthquake}

A devastating earthquake hit Japan on March 11, 2011, which caused a tsunami and triggered a nuclear accident at Fukushima. The Great East Japan Earthquake is considered one of the most catastrophic events in human history. The earthquake occurred off the coast of Japan and its magnitude was estimated as 9.0 (Daily Yomiuri 2011a), which was the fourth largest recorded earthquake in history.

The disaster was a composite one because of the devastating tsunami as an outcome of the earthquake. The powerful tsunami waves pushed water up to heights of more than 20 meters in some coastal areas of the northeastern coast of Japan (Daily Yomiuri 2011b). ${ }^{4}$ People on the coast were unable to escape from the tsunami and approximately 16,000 people died (National Police Agency 2014). In addition, residents in the prefectures of Iwate, Miyagi, and Fukushima suffered devastating damage because these prefectures have a coastline in their northeast regions. ${ }^{5}$ In this paper, the damaged area is defined as the area covering these three prefectures. Before the disaster, the damaged areas were experiencing depopulation and their populations were

\footnotetext{
3 Ono (2012) pointed out that interpersonal networks are effective and play an important role in deterring rioting and turmoil in the stricken areas affected by the Great East Japan Earthquake.

${ }^{4}$ Material losses of building and road infrastructure was calculated at 31.8 and 2.1 million tons, respectively (Tanikawa et al. 2014). The "World Bank and Japanese government say that there's somewhere between $\$ 122$ billion and $\$ 235$ billion worth of damage to clean up" (Hammer 2011:28).

5 A Japanese prefecture is almost the equivalent of a state in the United States or a province in Canada. There are 47 prefectures in Japan.
} 
decreasing, with the exception of Sendai in Miyagi prefecture. ${ }^{6}$ Before the disaster, in 2008-2009, the population decreased by $8.7 \%$, 6.0\%, and $0.7 \%$ in Iwate, Fukushima, and Miyagi prefectures, respectively. ${ }^{7}$

Even though disaster victims experienced many difficulties in the emergent situation, they were not confused and did not act impatiently, which helped to preserve public order. Looting and robbery were not observed in the stricken area (Ono 2012). In addition, instead of turmoil or rioting, altruistic behavior towards the victims of the disaster was observed in Japan. Victims of the disaster assisted each other (Kawachi 2013:15-16). Prior to the Great East Japan Earthquake, in 1995, the Great Hanshin-Awaji Earthquake hit Japan and caused catastrophic damage. However, a large number of young people volunteered in Kobe, which was directly hit by the earthquake. The Great Hanshin-Awaji Earthquake greatly motivated people to volunteer (Yamamura 2014). A similar phenomenon was observed after the Great East Japan Earthquake, for example, 13-year-old boys performed volunteer work in the stricken area with their fathers and "in the car on our way home, the boys all told that they wanted to volunteer again in Tohoku" (Matsutani 2011).

\section{Data and Hypothesis}

\subsection{Data}

In this paper, we use data from the Survey of Life Satisfaction and Preferences. As a part of the Global Center of Excellence (GCOE) program, Human Behavior and Socioeconomic Dynamics performed by Osaka University, the data were purposefully compiled to scrutinize the individual subjective perception from a socioeconomics perspective. Hereafter, this data are called GCOE data.

Since 2004, the panel survey has been conducted annually to cover all parts of Japan. The collection of data is based on the random-sampling method. Respondents are

\footnotetext{
${ }^{6}$ Sendai is regarded as the most urbanized city in northeastern Japan and has a population of over a million people.

The data is available from the Web site of the Statistics Bureau of the Ministry of Internal Affairs and Communications.

http://www.e-stat.go.jp/SG1/estat/NewList.do?tid=000000090001 (Accessed on June 9, 2014).
} 
male and female adults aged between 20 and 69 years. The data provided information regarding basic socioeconomic individual characteristics such as age, sex, household income, family members, degree of generalized trust, and degree of happiness, and residential place. New respondents were added to the survey waves in 2004, 2006, and 2009. Questions concerning the key variables such as generalized trust and happiness were only included in the questionnaire during the 2010-2013 surveys. Therefore, data used in this paper covered only four years (2010-2013). The survey was conducted from January to February each year. Therefore, the 2011 data were already collected when the Great East Japan Earthquake occurred in March 11. Therefore, the data from 2010 and 2011 can be defined as predisaster data while the data from 2012 and 2013 can be defined as postdisaster data.

Existing research examining the relationship between trust and happiness were not based on individual-level panel data (e.g., Bjørnskov 2003, 2006; Helliwell 2003, 2006a, 2006b; Ram 2009; Kuroki 2011). It is crucial to eliminate the individual time-invariant traits and follow the same individuals to scrutinize how SWB is determined (Powdthavee 2010:49-73). The great advantage of the panel GCOE data is that they allows us to follow the same individuals and control for individual fixed effects when we analyze the relationship between trust and happiness. Hence, this paper is anticipated to indicate the robustness of these works.

Table 1 shows the definitions of variables used in this paper and their mean values during the period 2010-2013. Table 1 also presents the mean difference test between residents in the damaged area and those in other areas. Key variables were Happiness, Trust, After disaster, and Damaged.

To identify the happiness level of respondents with a questionnaire, they were asked, "How would you rate you current level of happiness?" Their responses were scored on an 11-point Likert scale, which is used to measure the degree of happiness from 0 (very unhappy) to 10 (very happy). To identify the trust level of respondents, they were asked whether, "In general, most people are trustworthy?" Their responses were scored on a 5-point Likert scale from 1 (completely disagree) to 5 (completely disagree).

The mean value for Happiness in the damaged area was 6.32, which is smaller 
than in other areas (6.48). Furthermore, the difference was statistically significant at the $1 \%$ level. Therefore, on average, residents in the damaged area reported a 0.16-point lower happiness level on the 11-point scale compared with residents in other areas. However, there was no statistical significance even though the mean value for Trust in the residents from the damaged area is slightly larger than for other areas. That is, the trust level of residents in the damaged area was almost equivalent to that of residents in other areas.

The mean value for Income for residents in the damaged area was 5.93 million yen, which was significantly smaller than that for those in other areas. The variable Family for residents in the damaged area was 4.40, which was significantly larger than for residents in other areas (4.02). In the dataset, residential places were scaled into the classifications of large-sized city, medium-sized city, small city, and village (or town). ${ }^{8}$ Dummies for these were constructed, with the exception of large-sized city because a large-sized city was defined as the reference group in this paper. Mean values of dummies of Medium city, Small city, and Village for residents in the damaged area were $0.32,0.29$, and 0.12 , respectively. We can interpret this as indicating that when the sample was restricted to the damaged area, $32 \%, 29 \%$, and $12 \%$ of respondents resided in the medium-sized city, small city, and village (or town), respectively. However, the mean values of dummies of Medium city, Small city, and Village for residents in other areas were $0.42,0.22$, and 0.08 , respectively. We can interpret this as indicating that when the sample was restricted to other areas, $42 \%, 22 \%$, and $8 \%$ of respondents resided in the medium-sized city, small city, and village (or town), respectively. Respondents in the damaged area were more likely to reside in a small city or village (or town) than in other areas. These values show that the damaged areas can be characterized as having lower income, larger family size, and less urbanization.

\subsection{Hypotheses}

Using the GCOE data, Figure 1 shows the mean values of trust and happiness in each prefecture to illustrate the association between trust and happiness. A cursory

8 The GCOE data provide information about the name of prefecture and the size of the local government where the respondents resided. A prefecture consists of local governments, including many cities, towns, and villages. 
examination of Figure 1 reveals a positive association, which is in line with existing works (e.g., Bjørnskov 2003; Kuroki 2011). Figure 2 illustrates the change of happiness level based on subsample of residents of the damaged area and of other areas. During the study period, the happiness level of residents in the damaged area was smaller than that of other areas. This might reflect that most of the damaged areas appeared to experience a depopulation problem and their populations were already decreasing before the disaster, with the exception of Sendai in Miyagi Prefecture. The happiness level in the damaged area has clearly declined after the disaster in 2012 compared with the happiness levels in January or February of 2011 before the disaster. By 2013, the happiness level in the damaged area increased to a level almost equivalent to the level before the disaster. These findings imply that the disaster had a detrimental effect on happiness levels, but the effect is seemingly not persistent. Despite the enormous material damage caused by the disaster, people affected by the disaster have adapted to their situation 2 years later. In comparison, the happiness level in other areas has maintained almost the same level during this period. Therefore, the disaster was unlikely to influence the happiness level of people who resided in other areas unaffected by the disaster.

Figure 3 demonstrates the change in Trust based on the subsample of residents from the damaged area and the sample of residents in other areas. The level of trust increased for residents in the damaged area from 2010 to 2011, which indicated that people tended to increasingly trust others before the disaster. From 2011 to 2012, the level of trust declined, which possibly reflected the effect of the disaster. That is, the natural disaster decreased the level of trust, which is incongruent with the findings by Toya and Skidmore (2012). This may partly be because Toya and Skidmore (2012) used cross-country data instead of individual-level data. In 2013, the trust level had recovered to a level almost equivalent to that before the disaster. We argue that these findings show that the trust level is stable unless a disaster occurs. However, the level of trust of residents in other areas was smaller than that of residents in the damaged area before the disaster. However, this level of trust in other areas had caught up with levels of trust in the damaged area after the disaster. Overall, the levels of trust in other areas increased consistently during this period. 
Following existing works (Bjørnskov 2003, 2006; Helliwell 2003, 2006a, 2006b; Kuroki 2011), we postulate Hypothesis 1:

Hypothesis 1: $\quad$ Trust is positively associated with happiness.

The importance of social trust is expected to be acknowledged widely after suffering damage caused by a natural disaster, which leads people to trust others (Toya and Skidmore 2012). People are very uneasy after a disaster. In this situation, trust is thought to alleviate their uneasiness. Therefore, we provide Hypothesis 2:

Hypothesis 2: The positive relationship between trust and happiness is stronger after a disaster than before a disaster.

Damage from the disaster differed between the area where the earthquake and tsunami directly hit and other places. It is appropriate to assume that the post-disaster situation is more emergent and serious in the damaged area than in other areas. Markets and formal institutions are less likely to function well in the damaged area. In this situation, trust plays an important role in maintaining order and preventing the population from rioting. In a more emergent and serious situation, maintaining law and order is more valuable and important to keep mental conditions stable. Therefore, we propose Hypothesis 3:

Hypothesis 3: $\quad$ Trust is more strongly related to happiness in the damaged area after the disaster than before the disaster.

\subsection{Method}

The strategy of our estimation is roughly sketched as below; the purpose is to examine the effect of disaster and trust in 2011 on the Japanese happiness level. First, we simply compared residents living in other areas with residents in the prefectures hit by the earthquake in 2011. We focused on the effect of levels of trust. ${ }^{9}$

${ }^{9}$ It should be noted that this paper checks only the correlation between trust and 
To test Hypothesis 1, the estimated function takes the following form:

Happiness $_{i t p}=\alpha_{1}$ After disaster $_{t}+\alpha_{2}$ Trust $_{i t p}+Y^{\prime}{ }_{i t p} B+k_{i}+u_{i t p}$,

where Happiness itp represents the dependent variable in individual $i$, year $t$, and prefecture $p . k_{i}$ represents time-invariant individual-level fixed effects. Time-invariant features such as schooling years and gender dummy are completely captured by $k_{i}$ and are not included as independent variables. The regression parameters are denoted by $\alpha$. $Y$ is the vector of the individual-level control variables, which capture the influence of the various respondents' individual characteristics. Its vector of the regression parameters is denoted as $B$. The error term is denoted by $u$. After disaster takes 1 when observations are collected in 2011 or 2012, otherwise 0. If the disaster decreases happiness level, the predicted sign of After disaster is negative. Then, Trust is expected to show a positive sign if Hypothesis 1 is supported.

To examine Hypothesis 2, the function form is described below:

Happiness $_{i t p}=\beta_{1}$ After disaster $_{t} \times$ Trust $_{i t p}+\beta_{2}$ After disaster $_{t}+\beta_{3}$ Trust $_{i t p}+Y_{i t p}^{\prime} B+$ $k_{i}+u_{i t p}$

If the coefficient of After disaster ${ }_{t} \times$ Trust has a positive sign, trust is more positive and strongly related to happiness after the disaster than before the disaster. Therefore, from Hypothesis 2, Disaster ${ }_{t} \times$ Trust is expected to show a positive sign.

To examine Hypothesis 3, the function form is described below:

Happiness $_{i t p}=\gamma_{1}$ After disaster $_{t} \times$ Trust $_{i t p} \times$ Damaged $_{p}+\gamma_{2}$ After disaster $_{t} \times$ Trust $_{i t p}$ $+\gamma_{3}$ After disaster $_{t} \times$ Damaged $_{p}+\gamma_{4}$ After disaster $_{t}+\gamma_{5}$ Trust $_{i t p}+Y^{\prime}{ }_{i t p} B+k_{i}+u_{i t p}$.

In the model suggested above, if the coefficient of After disaster ${ }_{t} \times$ Trust $\times$ Damaged

happiness although there seems to be reverse causality and therefore endogenous bias. The instrumental variables must be used to control for this bias (Kuroki 2011). However, this is beyond the scope of this paper because the appropriate instruments cannot be obtained. 
takes a positive sign, the positive relation between trust and happiness for those who suffered from disaster become stronger. Hence, from Hypothesis 3, the sign of the coefficient of After Disaster ${ }_{t} \times$ Trust $\times$ Damaged is predicted to be positive. For the control variables, household income was included to examine the effect of income on happiness levels. In the fixed-effects model employed in this paper, the variation of income for the same individual is captured during the period 2010-2013. Apart from the income level as an independent variable to control factors related to happiness levels, this work also incorporates respondent ages, dummies for marital status, number of family members (Family), and dummies for residential places. The effect of age on happiness was found to be nonlinear (e.g., Clark and Oswald 1996; Blanchflower and Oswald 2004; Kuroki 2011). Therefore, with the aim of testing the nonlinear effect of age, in addition to Age, Age squared is included. Marital status is known to affect happiness levels (e.g., Oswald and Powdthavee 2008; Powdthavee 2008; Clark et al. 2008; Frijters et al. 2011). Therefore, three dummies (Unmarried, Divorce, and Widow) are included to capture marital status when currently married people are used as the reference group. As mentioned earlier, the damaged area is mainly a small-scale rural and depopulated place. However, the damaged area also includes Sendai, which is the most urbanized city in northeastern Japan. This variation in residential places should be controlled for. This work includes three dummies for residential place (Medium city, Small city, and Village) when the large-sized city is used as the reference group. In addition, eight occupation dummies (agriculture, fishery, constructing, or education), and seven residence dummies (private rented house, public rented house, company owned house, or apartment house) are included.

\section{$3 \quad$ Results}

Tables 2, 3, and 4 exhibit the estimation results using a fixed-effects model. Table 2 shows the results where the cross term is not included and Hypothesis 1 is examined. Table 3 shows the results of the model including where the cross term of After disaster ${ }_{t}$ $\times$ Trust is included to examine Hypothesis 2 . Table 4 presents the results of the model including where the cross term of three variables such as Disaster ${ }_{t} \times$ Trust $\times$ Damaged is included to test Hypothesis 3. In each table, the results of four different specifications 
are presented for the sake of a robustness check of results. The sample size increases when the number of control variables reduces because some observations do not provide information about the control variables. To focus on the key variable results, the results of control variables reported in Table 2 were not reported in Tables 3 and 4 even though the results of each column include the set of control variables equivalent to those of Table 2. Although not reported, the dummies of occupations and of types of residence are included in Tables $2-4$.

We see from Table 2 that the after-disaster dummy (covering the period 2012-2013) show a positive sign in all results, which is consistent with previous work exploring the effect of the Great East Japan Earthquake (Ishino et al. 2011; Uchida et al. 2014). However, After disaster was not statistically significant, which shows that there is no statistical difference in happiness levels before and after the disaster. Consistent with our prediction, the coefficient of Trust yields a positive sign and was statistically significant at the $1 \%$ level in all columns. Hypothesis 1 is strongly supported. Income yields a positive sign and is statistically significant at the $1 \%$ level, which is consistent with our prediction. In the result shown in column (4) of Table 2, the absolute value of the coefficient of Trust is 0.09 , which indicates that trust increases by 1 point, leading to an increase in happiness by 0.09 points on the 11-point Likert scale. However, the absolute value of the coefficient of Income is 0.014, which implies that household income increases by 1 million yen, leading to an increase in happiness by 0.014 points on the 11-point Likert scale. Therefore, the effect of a 1-point increase in Trust on the 5-point Likert scale is almost equivalent to an increase in 6.4 million yen (US\$80,000). ${ }^{10}$ Based on the whole GCOE data sample, the average household income is around 6.3 million yen. Therefore, the effect of a 1-point increase in Trust on the 5-point Likert scale is considered to be approximately equivalent to the average annual income in Japan. This is an exceedingly large value, which seems to reflect the estimation bias of income effects. Therefore, its effect is thought to decrease drastically after correcting for the bias (Powdthavee 2010:86-91). ${ }^{11}$ Instead of household income,

${ }^{10}$ Evaluation in US dollars is calculated based on the average foreign exchange rate in 2011. This method was also applied in the other parts to evaluate the effect of trust.

${ }^{11}$ Analysis using US data found that life events such as being widowed or marital separation would make it necessary to provide an individual with US $\$ 100,000$ extra per 
let us consider the effect of trust by using a marital status dummy (Unmarried). The coefficient's absolute value of Unmarried is 0.35 and its sign is negative, which means that unmarried people's happiness levels were lower by 0.35 points than for married people. Therefore, a 4-point increase in Trust compensates for the gap in happiness between married and unmarred people. ${ }^{12}$

As for other control variables, the sign of coefficient of Age and Age squared is negative and positive, respectively. Furthermore, they are statistically significant in columns (3) and (4). This indicated that the relationship between age and happiness is U-shaped, as often found in the happiness literature (Clark and Oswald 1996; Blanchflower and Oswald 2004; Kuroki 2011). With respect to marital status, the coefficient of Unmarried, Divorced, and Widow has the negative sign in all estimations. They are almost statistically significant, which is in line with previous work (e.g., Oswald and Powdthavee 2008; Powdthavee 2008; Clark et al. 2008; Frijters et al. 2011). ${ }^{13}$ Turning to scales of residential area, Medium city, Small city, and Village shows positive signs, with the exception of Small city. However, they are not statistically significant in any column, which suggests that there is no difference in happiness level between scales of residential place. Eight occupation dummies and seven residence dummies are included in the specification presented in column (4). None show statistical significance; therefore, happiness levels do not differ between occupations and types of residence although this is not reported in Table 2.

We now focus on the cross term between the after disaster dummy and degree of trust in Table 3. The sign of After disaster $\times$ Trust is negative while being statistically insignificant, which is not consistent with Hypothesis 2. Conversely, Trust shows a positive sign and is statistically significant at the $1 \%$ level. Therefore, the relationship between trust and happiness does not change after the disaster in Japan although trust is positively related to happiness.

annum (Blanchflower and Oswald 2004:1373).

12 In monetary terms, approximately US $\$ 300,000$ compensates for the gap in happiness between married and unmarried people, which is equivalent to the UK (Powdthavee 2010:88).

${ }^{13}$ Existing works also provided evidence that the effect of divorce (or death of spouses) on happiness is not persistent several years after the event (e.g., Oswald and Powdthavee 2008; Clark et al. 2008; Frijters et al. 2011). 
Table 4 shows that the cross term among three variables such as After disaster $\times$ Trust $\times$ Damaged produces a positive sign and is statistically significant in all columns. The positive relationship between trust and happiness became stronger for residents in the damaged area than in other areas after the disaster. This strongly supported Hypothesis 3. Apart from this, it is interesting to observe that the coefficient of After disaster $\times$ Damaged shows the negative sign while being statistically significant in all columns. The happiness level for residents in the damaged area declined directly after the disaster, which is in line with Figure 2. Furthermore, considering the results of After disaster in Table 2 and of After disaster $\times$ Damaged leads us to claim that the disaster reduced the happiness levels in the damaged area, but did not change it throughout Japan. Trust continues to show a significant positive sign in columns (1)-(4). The discussion of the results shown in Tables 2-4 strongly supports Hypotheses 1 and 3.

In discussing the economic significance derived from the results shown in Table 4, we now turn to the absolute values of the coefficients of cross terms presented in column (4). The absolute value of the coefficient of After disaster $\times$ Trust $\times$ Damaged is 0.36 , while that of After disaster $\times$ Damaged is 1.30 . These can be interpreted as follows. Compared with other areas after the disaster, the happiness level of residents in the damaged area is 1.30 points smaller when the effect of trust is not considered. The value of the coefficient of Income is 0.014 even though it is not reported in Table 4. That is, the negative effect of the disaster is estimated to be compensated by 93 million yen (US\$1.2 million), which is considered as a gigantic amount. However, as mentioned earlier, it should be noted that the estimated amount of compensation was overestimated because of the endogeneity bias (Powdthavee 2010). An increase in trust by 1 point on the 5-point Likert scale leads to an increase in happiness by 0.36 points. This means that a 1-point increase of trust for residents of damaged areas reduces the gap of happiness levels from residents of other areas by 0.36 points. Therefore, the happiness level of residents in the damaged area is 0.22 points smaller than those in other areas if the trust level is 3. However, the happiness level of residents in the damaged area is 0.14 points larger than those in other areas if the trust level is 4 . That is, the happiness level of residents in the damaged areas is possibly higher than others if their trust level is 4 or 5 . Therefore, the effect of trust is sizable on SWB and becomes crucial as a remedy for an 
unpredictable, gigantic shock such as a disaster.

\section{Conclusion}

The outcome of unexpected terrors has drawn the attention of researchers. Its psychological impact on life satisfaction has been increasingly explored in empirical works on natural disasters (Carroll et al. 2009; Luechinger and Saschkly 2009) and terrorism (Metcalfe et al. 2011). Social trust is known to be positively associated with life satisfaction (Bjørnskov 2003). The effectiveness of social trust possibly depends on the situation. For instance, formal institutions and markets do not function well immediately after an unexpected, devastating event. In this case, trust towards others appears to become more important for avoiding chaos and turmoil. The role of social trust in the chaotic situation after the disaster is worth analyzing because distrust deteriorates the situation and in turn reduces social welfare. However, existing works did not probe how and the extent to which the relationship between trust and happiness changes after the disastrous event.

To deal with the relationship between trust and happiness after the disaster, this paper used the individual-level panel data from Japan, which covered the period before and after the Great East Japan Earthquake. By employing fixed-effects estimations, we found that there is a positive relationship between trust and happiness and this relationship is strengthened for residents in the damaged area. This finding implies that social trust plays a greater role in increasing happiness during a chaotic situation than in time of peace. We therefore derived the argument that social trust is a substitute for formal institutions and markets to mitigate the shock of disaster on psychological conditions such as happiness. Therefore, a trustful society is invulnerable to a gigantic disaster.

Of course, there is an endogenous bias when trust is included as an independent variable and so causality is ambiguous. Before the disaster, trust and happiness levels differed between residents in the damaged area and other areas. It is more appropriate to conduct an examination in the case that these values of residents living in the damaged area are almost as the same as those of residents living in other areas before the disaster. For closer examination, it is important to use instrumental variables to control for 
endogenous bias, although it is difficult to identify the instrumental variables. Furthermore, conditions before the event should be similar between the damaged areas and other areas. Therefore, it is also worth conducting experiments in similar situations before a disastrous event (Becchetti et al. 2012). These are remaining issues to be addressed by future research.

\section{Acknowledgement}

This research uses microdata from the Preference Parameters Study of Osaka University's 21st Century GCOE program, Behavioral Macrodynamics based on Surveys and Experiments, and its GCOE project, Human Behavior and Socioeconomic Dynamics. We acknowledge the contribution from the program and project contributors: Yoshiro Tsutsui, Fumio Ohtake, and Shinsuke Ikeda.

The first author gratefully acknowledge financial support in the form of research grants from the Japan Center for Economic Research as well as the Japanese Society for the Promotion of Science (Foundation C 20368971, PI: Eiji Yamamura). Further, the first author wishes to acknowledge the financial support of The Kikawada Foundation.

\section{References}

Aldrich, D. P. (2012). Building resilience: Social capital in post-disaster recovery. Chicago: University Chicago Press.

Anbarci, N., Escaleras, M., \& Register, C. (2005). Earthquake fatalities: the interaction nature and political economy. Journal of Public Economics, 89(9-10), 1907-1933.

Becchetti, L., \& Castriota, S. (2010). The effects of a calamity on income and wellbeing of poor microfinance borrowers: the case of the 2004 tsunami shock. Journal of Development Studies, 46(2), 211-233.

Becchetti, L., Castriota, S., \& Conzo, P. (2012). Calamity, aid and indirect reciprocity: the long run impact of tsunami. CEIS (Tor Vergata University) Research Paper, no. 239.

Bjørnskov, C. (2003). The happy few: cross-country evidence on social capital and life 
satisfaction. Kyklos, 56(1), 3-16.

Bjørnskov, C. (2006). The multiple facets of social capital. European Journal of Political Economy, 22(1), 22-40.

Blanchflower, D. G., \& Oswald, A. (2004). Well-being over time in Britain and the USA. Journal of Public Economics, 88(7-8), 1359-1386.

Carroll, N., Frijters, P., \& Shields, M. (2009). Quantifying the costs of drought: new evidence from life satisfaction data. Journal of Population Economics, 22(2), $445-461$.

Clark, A., \& Oswald, A. (1996). Satisfaction and comparison income. Journal of Public Economics, 61(3), 359-381.

Clark, A., Diener, E., Georgellis, Y., \& Lucas, R. E. (2008). Lags and leads in life satisfaction: a test of the baseline hypothesis. The Economic Journal, 118(529), F222-F2243.

Daily Yomiuri. (2011a). 2000 missing in 2 towns: Magnitude of Friday's quake revised upward to 9.0. March 14, 2011. Daily Yomiuri.

Daily Yomiuri. (2011b). Tsunami topped 15 meters on Sanriku coast. March 19, 2011. Daily Yomiuri.

Eisensee, T., \& Strömberg, D. (2007). News droughts, news floods, and U.S. disaster relief. Quarterly Journal of Economics, 122(2), 693-728.

Frijters, P., Johnston, D. W., \& Shields, M. A. (2011). Life satisfaction dynamics with quarterly life event data. Scandinavian Journal of Economics, 113(1), 190-211.

Goebel, J., Krekel, C., Tiefenbach, T., \& Ziebarth, N. R. (2013). Natural disaster, policy action, and mental well-being: the case of Fukushima. IZA Discussion Papers, no. 7691.

Hammer, J. (2011). Inside the danger zone. April 11, 2011. Newsweek, 28-31.

Hanaoka, C., Shigeoka, H., \& Watanabe, Y. (2014). Do risk preferences change? evidence from panel data before and after the great east Japan earthquake. Mimeo.

Helliwell, J. F. (2003). How's life? Combining individual and national variables to explain subjective well-being. Economic Modelling, 20(2), 331-360.

Helliwell, J. F. (2006a). Well-being and social capital: does suicide pose a puzzle? Social Indicator Research, 81(3), 455-496. 
Helliwell, J. F. (2006b). Well-being, social capital and public policy: What's new? The Economic Journal, 116(510), C34-45.

Ishino, T., Ogaki, M., Kamesaka, A., \& Murai, S. (2011). Effect of the great East Japan disaster on Happiness. Keio/Kyoto Global COE Discussion Paper Series, DP2011-38.

Kawachi, I. (2013). Can we reduce disparity of life? (In Japanese). Inochi no Kakusa wa Tomerareruka. Tokyo: Shogakkan Press.

Kawachi, I., Kennedy, B .P., Lochner, K., \& Prothrow-stith, D. (1997). Social capital, income inequality, and mortality. American Journal of Public Health, 87(9), $1491-1498$.

Kawachi, I., Kennedy, B .P., Lochner, K., \& Glass, R. (1999). Social capital and self-related health: a contextual analysis. American Journal of Public Health, 89(9), 1187-1193.

Kawachi, I., Subramanian, S. V., \& Kim, D. (Eds). (2007). Social capital and health. New York: Springer.

Kellenberg, D. K., \& Mobarak, A. M. (2008). Does rising income increase or decrease damage risk from natural disasters? Journal of Urban Economics, 63(3), 788-802.

Kuroki, M. (2011). Does social trust increase individual happiness in Japan? Japanese Economic Review, 62(4), 444-459.

Luechinger, S., \& Saschkly, P. A. (2009). Valuing flood disasters using the life satisfaction approach. Journal of Public Economics, 93(3-4), 620-633.

Matsubayashi, T., Sawada, Y., \& Ueda, M. (2013). Natural disasters and suicide: Evidence from Japan. Social Science \& Medicine, 82, 126-133.

Matsutani, M. (2011). Volunteering with three teens in Tohoku. July 17, 2011. The Japan Times.

Metcalfe, R., Powdthavee, N., \& Dolan, P. (2011). Destruction and distress: using a quasi-experiment to show the effects of the September 11 attacks on mental well-being in the United Kingdom. The Economic Journal, 121(550), F81-F103.

National Police Agency. (2014). The damage of the Great East Japan Earthquake (in Japanese). (Higashi Nihon Daishinsai no Higaijokyo). http://www.npa.go.jp/archive/keibi/biki/higaijokyo.pdf (Accessed on June 15, 
2014).

Ono, H. (2012). The reason that disturbance does not arise after the disaster in Japan: Consideration from the angle of network theory (in Japanese). (Nihon dewa naze shinsaigo ni bodo ga okinai noka: netwaork riron karano ichi-kosatsu) Keizai Seminar, (2-3), 75-79.

Oswald, A., \& Powdthavee, N. (2008). Death, happiness, and the calculation of compensatory damages. Journal of Legal Studies, 37(S2), S217-252.

Powdthavee, N. (2008). Putting a price tag on friends, relatives and neighbours: Using surveys of life satisfaction to value social relations. Journal of Socio-economics, 37(4), 1459-1480.

Powdthavee, N. (2010). The happiness equation: The surprising economics of our most valuable asset. London: Icon Books.

Putnam, R. (1993). Making democracy work: Civic traditions in modern Italy. Princeton: Princeton University Press.

Putnam, R. (2000). Bowling alone: The collapse and revival of American community. New York: A Touchstone Book.

Ram, R. (2009). Social capital and happiness: additional cross-country evidence. Journal of Happiness Studies, 11(4), 409-418.

Sawada, Y., \& Shimizutani, S. (2007). Consumption insurance against natural disasters: evidence from the Great Hanshin-Awaji (Kobe) earthquake. Applied Economics Letters, 14(4), 303-306.

Sawada, Y., \& Shimizutani, S. (2008). How do people cope with natural disasters? Evidence from the Great Hanshin-Awaji (Kobe) Earthquake in 1995. Journal of Money, Credit and Banking, 40(2-3), 463-488.

Sawada, Y., \& Shimizutani, S., (2011). Changes in durable stocks, portfolio allocation, and consumption expenditure in the aftermath of the Kobe Earthquake. Review of Economics of the Household, 9(4), 429-443.

Skidmore, M., \& Toya, H. 2002. Do natural disasters promote long-run growth? Economic Inquiry, 40(4), 664-687.

Tanikawa, H., Managi, S., \& Lwin, C. M. (2014). Estimates of lost material stock of buildings and roads due to the Great East Japan Earthquake and tsunami. Journal 
of Industrial Ecology, Forthcoming.

Toya, H., \& Skidmore, M. (2012). Do natural disasters enhance societal trust? CESifo Working Papers, no. 3905.

Uchida, Y., Takahashi, Y., \& Kawahara, K. (2014). Changes in hedonic and eudaimonic well-being after a severe nationwide disaster: The case of the Great East Japan Earthquake. Journal of Happiness Studies, 15(1), 207-221.

Yamamura, E. (2010). Effects of interactions among social capital, income and learning from experiences of natural disasters: a case study from Japan. Regional Studies, 44(8), 1019-1032.

Yamamura, E. (2014). Natural disasters and social capital formation: The impact of the Great Hanshin-Awaji earthquake. Papers in Regional Science, Forthcoming. 


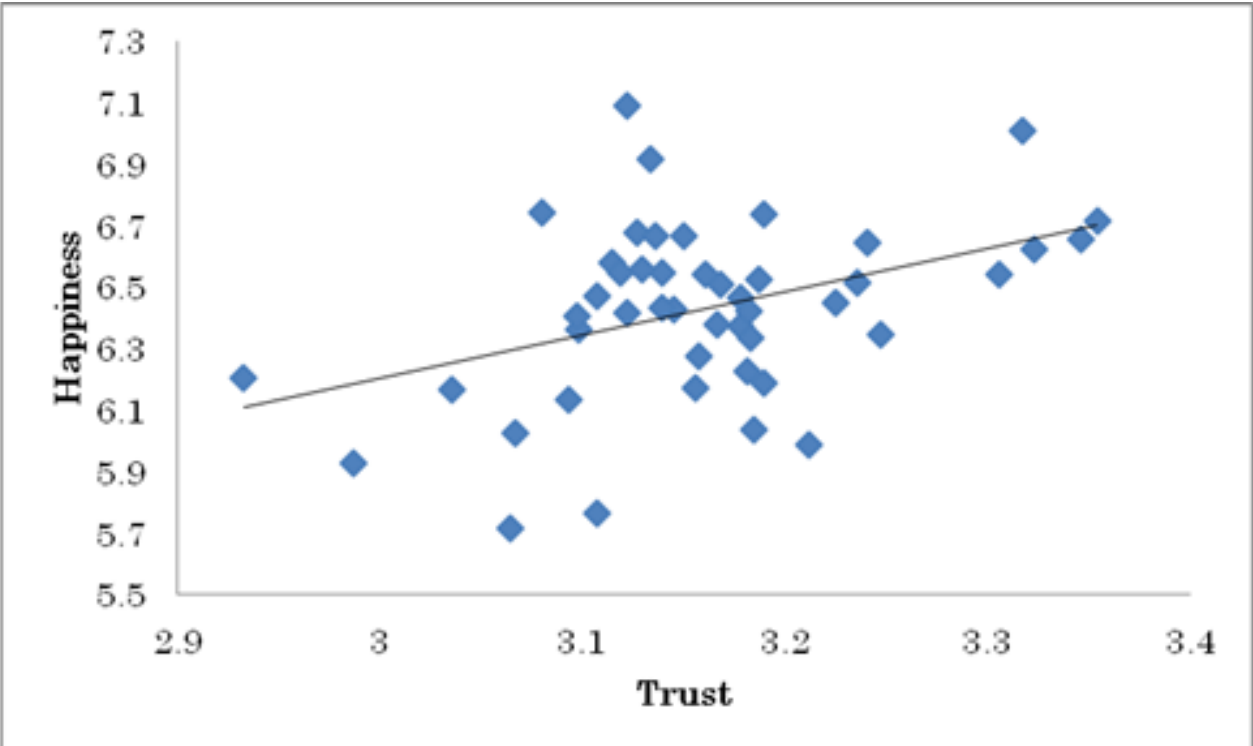

Figure 1. Association between trust and happiness. 


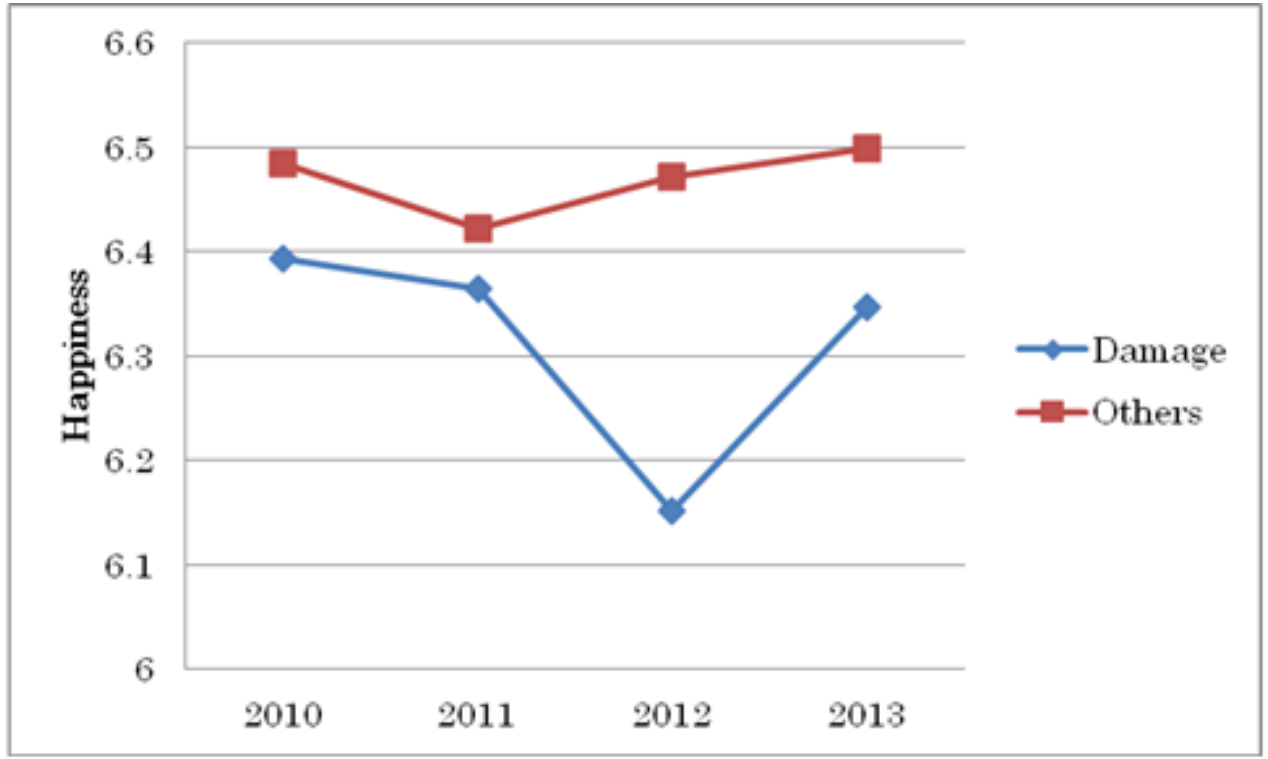

Figure 2. Change of happiness level 


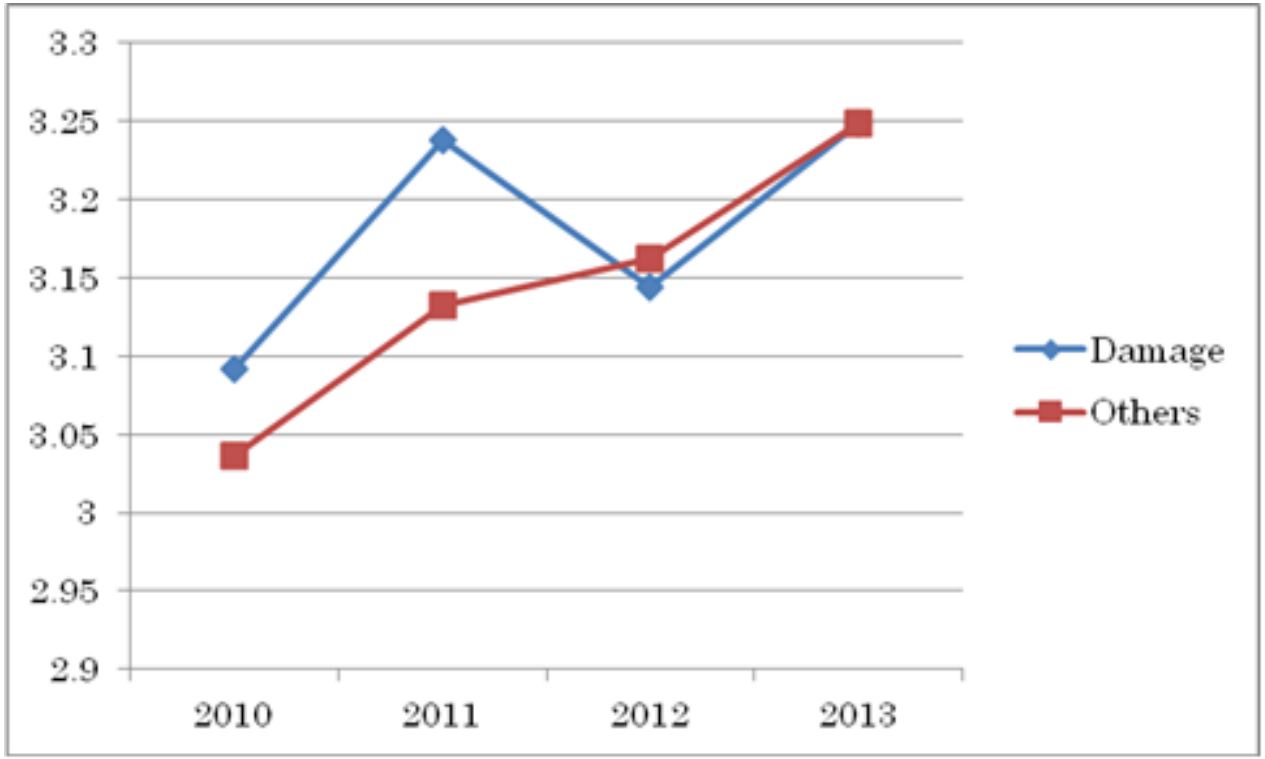

Figure 3. Change of trust level 
Table 1. Definition of variables used for estimation and its comparison between the damaged areas and other areas.

\begin{tabular}{|c|c|c|c|c|}
\hline & Definitions & Damaged & Others & t-statistics \\
\hline Happiness & $\begin{array}{l}\text { The degree of happiness. } \\
\text { Question: How would you rate you current level of happiness? } \\
\text { 0(Very unhappy)- 10(Very happy) }\end{array}$ & 6.32 & 6.48 & $2.69 * * *$ \\
\hline Trust & $\begin{array}{l}\text { The degree of trust. } \\
\text { Question: In general, most people are trustworthy. } \\
\text { 1(completely disagree)- 5(completely agree) }\end{array}$ & 3.18 & 3.14 & 1.29 \\
\hline After disaster & It is 1 if the data was collected after the disaster (2011-2013), otherwise 0. & $\cdots$ & $-\cdots$ & $\cdots$ \\
\hline Damaged & $\begin{array}{l}\text { It is } 1 \text { if the data was collected in damaged areas (Iwate, Miyagi and } \\
\text { Fukushima prefectures), otherwise } 0 .\end{array}$ & ---- & $-\cdots$ & --- \\
\hline Age & Ages & 52.3 & 52.5 & 0.39 \\
\hline Age square & Square of ages & $-\cdots$ & --- & --- \\
\hline Man & It is 1 if respondent is man, otherwise 0 . & 0.53 & 0.45 & --- \\
\hline Income & House hold income (million yen) & 5.93 & 6.32 & $2.57 * *$ \\
\hline Unmarried & It is 1 if respondent is unmarried, other wise 0. & 0.13 & 0.12 & $-\cdots$ \\
\hline Divorce & It is 1 if respondent is divorced, other wise 0 . & 0.02 & 0.04 & $\cdots$ \\
\hline Widow & It is 1 if respondent is widow, other wise 0 . & 0.02 & 0.03 & --- \\
\hline Family & Number of family members. & 4.40 & 4.02 & $5.37 * * *$ \\
\hline Medium city & $\begin{array}{l}\text { It is } 1 \text { if the residential place is city with population }(100 \\
\text { thousand=<population }<200 \text { thousand), otherwise } 0 .\end{array}$ & 0.32 & 0.42 & --- \\
\hline Small city & $\begin{array}{l}\text { It is } 1 \text { if the residential place is city with population ( }<100 \text { thousand), } \\
\text { otherwise } 0 .\end{array}$ & 0.29 & 0.22 & $-\cdot-$ \\
\hline Village & It is 1 if the residential place is village or town, other wise 0. & 0.13 & 0.08 & $-\cdots$ \\
\hline
\end{tabular}

Note: The damaged areas are defined as Iwate, Miyagi and Fukushima prefectures. Numbers in parentheses are absolute value of $\mathrm{t}$-statistics for test of mean difference between the damaged and other areas. .*,** and *** indicate significance at the $10 \%, 5 \%$ and $1 \%$ levels, respectively. 
Table 2. Dependent variable is the happiness level (Fixed effects estimation).

\begin{tabular}{|c|c|c|c|c|}
\hline & (1) & (2) & (3) & (4) \\
\hline After disaster & $\begin{array}{l}0.03 \\
(1.00)\end{array}$ & $\begin{array}{l}0.04 \\
(1.19)\end{array}$ & $\begin{array}{l}0.04 \\
(1.17)\end{array}$ & $\begin{array}{l}0.02 \\
(0.52)\end{array}$ \\
\hline Trust & $\begin{array}{l}0.09 * * * \\
(5.21)\end{array}$ & $\begin{array}{l}0.10^{* * * *} \\
(5.43)\end{array}$ & $\begin{array}{l}0.09 * * * \\
(5.16)\end{array}$ & $\begin{array}{l}0.09 * * * \\
(5.04)\end{array}$ \\
\hline Age & $\begin{array}{l}-0.05 \\
(-1.51)\end{array}$ & $\begin{array}{l}-0.05 \\
(-1.48)\end{array}$ & $\begin{array}{l}-0.06^{*} \\
(-1.75)\end{array}$ & $\begin{array}{l}-0.06^{*} \\
(-1.74)\end{array}$ \\
\hline Age square & $\begin{array}{l}0.0004 \\
(1.63)\end{array}$ & $\begin{array}{l}0.0004 \\
(1.56)\end{array}$ & $\begin{array}{l}0.0005^{*} \\
(1.90)\end{array}$ & $\begin{array}{l}0.0006^{* *} \\
(2.09)\end{array}$ \\
\hline Income & & $\begin{array}{l}0.14^{* * * *} \\
(2.80)\end{array}$ & $\begin{array}{l}0.14^{* * *} \\
(2.81)\end{array}$ & $\begin{array}{l}0.14^{* * * *} \\
(2.82)\end{array}$ \\
\hline Unmarried & & & $\begin{array}{l}-0.40^{* * *} \\
(-2.54)\end{array}$ & $\begin{array}{l}-0.35^{* *} \\
(-2.11)\end{array}$ \\
\hline Divorce & & & $\begin{array}{l}-0.27^{*} \\
(-1.70)\end{array}$ & $\begin{array}{l}-0.15 \\
(-0.92)\end{array}$ \\
\hline Widow & & & $\begin{array}{l}-0.42^{* * *} \\
(-2.59)\end{array}$ & $\begin{array}{l}-0.39 * * \\
(-2.14)\end{array}$ \\
\hline Family & & & $\begin{array}{l}-0.001 \\
(-0.22)\end{array}$ & $\begin{array}{l}0.001 \\
(0.10)\end{array}$ \\
\hline Medium city & & & $\begin{array}{l}0.11 \\
(0.60)\end{array}$ & $\begin{array}{l}0.09 \\
(0.46)\end{array}$ \\
\hline Small city & & & $\begin{array}{l}-0.16 \\
(-0.42)\end{array}$ & $\begin{array}{l}0.002 \\
(0.01)\end{array}$ \\
\hline Village & & & $\begin{array}{l}0.24 \\
(0.82)\end{array}$ & $\begin{array}{l}0.21 \\
(0.71)\end{array}$ \\
\hline $\begin{array}{l}\text { Occupation } \\
\text { dummies }\end{array}$ & $\begin{array}{l}\text { Not } \\
\text { included }\end{array}$ & $\begin{array}{l}\text { Not } \\
\text { included }\end{array}$ & $\begin{array}{l}\text { Not } \\
\text { included }\end{array}$ & Included \\
\hline $\begin{array}{l}\text { Residence } \\
\text { dummies }\end{array}$ & $\begin{array}{l}\text { Not } \\
\text { included }\end{array}$ & $\begin{array}{l}\text { Not } \\
\text { included }\end{array}$ & $\begin{array}{l}\text { Not } \\
\text { included }\end{array}$ & Included \\
\hline Observations & 16,697 & 15,178 & 15059 & 14,379 \\
\hline
\end{tabular}

Note: Numbers in parentheses are t-statistics. $*, * *$ and $* * *$ indicate significance at the $10 \%, 5 \%$ and $1 \%$ levels, respectively. Occupation dummies capture various sectors where respondent work such as agriculture and fishery, mining, construction, financing, manufacturing, real estate, transportation, education, energy, service and others. Residence dummies capture types of residence such as detached house (in one's possession), private rented house, public rented house, company owned house, apartment house, rented room, dormitory and other one. 
Table 3. Dependent variable is the happiness level and independent variables include cross term between After disaster and Trust (Fixed effects estimation).

\begin{tabular}{|c|c|c|c|c|}
\hline & (1) & $(2)$ & (3) & (4) \\
\hline $\begin{array}{l}\text { After disaster } \\
{ }^{*} \text { Trust }\end{array}$ & $\begin{array}{l}-0.01 \\
(-0.42)\end{array}$ & $\begin{array}{l}-0.01 \\
(-0.78)\end{array}$ & $\begin{array}{l}-0.02 \\
(-0.83)\end{array}$ & $\begin{array}{l}-0.01 \\
(-0.72)\end{array}$ \\
\hline After disaster & $\begin{array}{l}0.06 \\
(0.80)\end{array}$ & $\begin{array}{l}0.10 \\
(1.21)\end{array}$ & $\begin{array}{l}0.10 \\
(1.24)\end{array}$ & $\begin{array}{l}0.08 \\
(0.88)\end{array}$ \\
\hline Trust & $\begin{array}{l}0.09 * * * \\
(4.60)\end{array}$ & $\begin{array}{l}0.10^{* * *} \\
(4.99)\end{array}$ & $\begin{array}{l}0.10^{* * *} \\
(4.79)\end{array}$ & $\begin{array}{l}0.10^{* * * *} \\
(4.65)\end{array}$ \\
\hline $\begin{array}{l}\text { Occupation } \\
\text { dummies }\end{array}$ & $\begin{array}{l}\text { Not } \\
\text { included }\end{array}$ & $\begin{array}{l}\text { Not } \\
\text { included }\end{array}$ & $\begin{array}{l}\text { Not } \\
\text { included }\end{array}$ & Included \\
\hline $\begin{array}{l}\text { Residence } \\
\text { dummies }\end{array}$ & $\begin{array}{l}\text { Not } \\
\text { included }\end{array}$ & $\begin{array}{l}\text { Not } \\
\text { included }\end{array}$ & $\begin{array}{l}\text { Not } \\
\text { included }\end{array}$ & Included \\
\hline Observations & 16,697 & 15,178 & 15059 & 14,379 \\
\hline
\end{tabular}

Note: Numbers in parentheses are t-statistics. $* *$ and $* * *$ indicate significance at the $5 \%$ and $1 \%$ levels, respectively. In all estimations, the set of variables used in Table 2 is included as independent variables, but they are not reported here. 
Table 4. Dependent variable is the happiness level and independent variables include cross terms between After disaster, Trust and Damaged (Fixed effects estimation).

\begin{tabular}{|c|c|c|c|c|}
\hline & (1) & (2) & (3) & (4) \\
\hline $\begin{array}{l}\text { After disaster } \\
{ }^{*} \text { Trust } \\
\text { *Damaged }\end{array}$ & $\begin{array}{l}0.24^{* *} \\
(2.11)\end{array}$ & $\begin{array}{l}0.29^{* *} \\
(2.31)\end{array}$ & $\begin{array}{l}0.32^{* *} \\
(2.57)\end{array}$ & $\begin{array}{l}0.36^{* * *} \\
(2.73)\end{array}$ \\
\hline $\begin{array}{l}\text { After disaster } \\
\text { *Trust }\end{array}$ & $\begin{array}{l}-0.02 \\
(-0.87)\end{array}$ & $\begin{array}{l}-0.03 \\
(-1.21)\end{array}$ & $\begin{array}{l}-0.03 \\
(-1.30)\end{array}$ & $\begin{array}{l}-0.03 \\
(-1.21)\end{array}$ \\
\hline $\begin{array}{l}\text { After disaster } \\
{ }^{*} \text { Damaged }\end{array}$ & $\begin{array}{l}-0.84^{* *} \\
(-2.31)\end{array}$ & $\begin{array}{l}-1.05^{* *} \\
(-2.54)\end{array}$ & $\begin{array}{l}-1.15^{* * *} \\
(-2.77)\end{array}$ & $\begin{array}{l}-1.30 * * * \\
(-2.98)\end{array}$ \\
\hline $\begin{array}{l}\text { Trust } \\
{ }^{*} \text { Damaged }\end{array}$ & $\begin{array}{l}-0.01 \\
(-0.02)\end{array}$ & $\begin{array}{l}0.02 \\
(0.20)\end{array}$ & $\begin{array}{l}0.01 \\
(0.18)\end{array}$ & $\begin{array}{l}0.01 \\
(0.12)\end{array}$ \\
\hline After disaster & $\begin{array}{l}0.10 \\
(1.26)\end{array}$ & $\begin{array}{l}0.14^{*} \\
(1.66)\end{array}$ & $\begin{array}{l}0.15^{*} \\
(1.74)\end{array}$ & $\begin{array}{l}0.13 \\
(1.39)\end{array}$ \\
\hline Trust & $\begin{array}{l}0.09 * * * \\
(4.48)\end{array}$ & $\begin{array}{l}0.10^{* * *} \\
(4.83)\end{array}$ & $\begin{array}{l}0.10^{* * * *} \\
(4.65)\end{array}$ & $\begin{array}{l}0.10^{* * * *} \\
(4.53)\end{array}$ \\
\hline $\begin{array}{l}\text { Occupation } \\
\text { dummies }\end{array}$ & $\begin{array}{l}\text { Not } \\
\text { included }\end{array}$ & $\begin{array}{l}\text { Not } \\
\text { included }\end{array}$ & $\begin{array}{l}\text { Not } \\
\text { included }\end{array}$ & Included \\
\hline $\begin{array}{l}\text { Residence } \\
\text { dummies }\end{array}$ & $\begin{array}{l}\text { Not } \\
\text { included }\end{array}$ & $\begin{array}{l}\text { Not } \\
\text { included }\end{array}$ & $\begin{array}{l}\text { Not } \\
\text { included }\end{array}$ & Included \\
\hline Observations & 16,697 & 15,178 & 15059 & 14,379 \\
\hline
\end{tabular}

Note: Effect of Damaged is completely captured by the fixed effects because respondents did not move between prefectures in the sample. Numbers in parentheses are t-statistics. $* *$ and $* * *$ indicate significance at the $5 \%$ and $1 \%$ levels, respectively. In all estimations, the set of variables used in Table 2 is included as independent variables, but they are not reported here. 